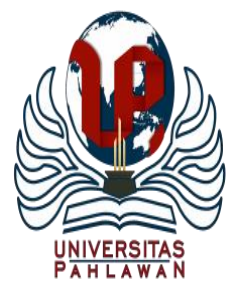

Jurnal Abdidas Volume 1 Nomor 5 Tahun 2020 Halaman 450 - 457

JURNAL ABDIDAS

$\underline{\text { http://abdidas.org/index.php/abdidas }}$

\title{
Pelatihan Keterampilan Desain Media Pembelajaran Tiga Dimensi Jenis Diorama Berbasis Tematik Integratif di Sekolah Dasar
}

\author{
Hijrawatil Aswat ${ }^{1}$, Mitrakasih La Ode Onde ${ }^{2}$, La Ode Madiani ${ }^{3}, \operatorname{Irsan}^{4}$ \\ Pendidikan Guru Sekolah Dasar, Universitas Muhammadiyah Buton ${ }^{1,2,3,4}$ \\ E-mail : hijrawati_aswat@yahoo.co.id ${ }^{1}$ Mitralaodeonde@gmail.com² $\underline{\text { Madiani.laode@gmail.com }{ }^{3}}$ \\ irsanlely@gmail.com ${ }^{4}$
}

\begin{abstract}
Abstrak
Salah satu pendukung efektivitas proses belajar mengajar di kelas khususnya di Sekolah Dasar adalah pelibatan media pembelajaran. Salah satu media yang dapat menampilkan objek dalam bentuk dan ukuran yang lebih kecil dan mudah dibawa di dalam kelas adalah media tiga dimensi jenis diorama. Karena jenis media ini didesain berwujud benda asli atau miniature yang penyajiannya secara visual tiga dimensi. Sehingga diperlukan pelatihan dan pendampingan kepada guruguru dalam mengembangkan keterampilannya dalam mendesain media diorama sesuai dengan langkah-langkah pembuatan yang benar dan mencakup pembelajaran tematik. Metode kegiatan ini diawali dengan observasi lapangan dengan meninjau masalah yang dihadapi sekolah salah satunya temuan kurangnya pemanfaatan media pembelajaran di kelas, selanjutnya menyusun rancangan pemecahan masalah melalui pelatihan pembuatan media diorama, dan tahap pelaksanaan. Kegiatan ini berlangsung selama 3 jam yang diikuti oleh guru Sekolah Dasar Negeri 1 Topa dengan diawali pemaparan materi seputar pemanfaatan media pembelajaran dan langkah pembuatan media diorama, selanjutnya praktik pembuatan media yang didampingi oleh narasumber. Kegiatan ini berjalan dengan lancar dan disambut baik oleh guru, ditandai dengan kemampuan guru dalam mendesain diorama secara kelompok dan mandiri sehingga memberikan pengalaman dan menambah khasanah keilmuan dalam pembuatan media pembelajaran diorama serta menumbuhkan motivasi guru dalam memenuhi kebutuhan siswa dan memberikan kemudahan kepada guru dalam mentransfer ilmu pengetahuan kepada siswa.
\end{abstract}

Kata kunci: media pembelajaran, diorama, keterampilan mendesain

\begin{abstract}
One of the supporters of the effectiveness of the teaching and learning process in the classroom, especially in elementary schools, is the involvement of learning media. One of the media that can display in smaller shapes and sizes and is easy to carry in the classroom is a diorama type three-dimensional media. Because this type of media is designed to be in the form of original objects or miniatures with a three-dimensional visual presentation. So that training and assistance is needed for teachers in developing their skills in designing diorama media in accordance with the correct manufacturing steps and includes thematic learning. The method of this activity begins with field observations by reviewing the problems faced by schools, one of which is the finding of the lack of use of instructional media in the classroom, then compiling a problem-solving plan through training in making diorama media, and the implementation stage of this activity lasts for 3 hours. 1 Topa begins with the presentation of material about the use of instructional media and the steps for making diorama media, then the practice of making media is accompanied by the resource person. This activity went well and was welcomed by the teacher, marked by the teacher's ability to design dioramas in groups and independently so as to provide experience and add knowledge in making diorama learning media as well as fostering teacher motivation in meeting student needs and providing convenience to teachers in transferring knowledge knowledge to students.
\end{abstract}

Keywords: learning media, dioramas, design skills

Copyright (c) 2020 Hijrawatil Aswat, Mitrakasih La Ode Onde, La Ode Madiani, Irsan

\begin{tabular}{l}
\hline$\triangle$ Corresponding author \\
Address $\quad:$ Betoambari No.36 Kota Baubau \\
Email $\quad:$ hijrawati_aswat@yahoo.co.id \\
Phone $\quad: 082346989061$ \\
DOI : https://doi.org/10.31004/abdidas.v1i5.87
\end{tabular}

ISSN 2721-9224 (Media Cetak)

ISSN 2721-9216 (Media Online) 


\section{PENDAHULUAN}

Pendidikan di Indonesia terus membenah seiring dengan kemajuan teknologi dan disesuaikan dengan kebutuhan siswa, terkhusus pada sekolah dasar salah satunya dengan penerapan pembelajaran tematik integratif. Munculnya pembelajaran tematik ini tentu tak lepas dari tujuan pendidikan nasional dalam "Undang-Undang Nomor 20 tahun 2003 tentang Sistem Pendidikan Nasional, pasal 3, tujuan pendidikan nasional adalah mengembangkan potensi peserta didik agar menjadi manusia yang beriman dan bertakwa kepada Tuhan Yang Maha Esa, berakhlak mulia, sehat, berilmu, cakap, kreatif, mandiri, dan menjadi warga negara yang demokratis serta bertanggung jawab. Pemerintah secara bertahap berusaha meningkatkan kualitas pendidikan diantaranya melakukan penyempurnaan sistem pendidikan ke kurikulum 2013 dengan menggunakan pembelajaran tematik integratif, bentuk upaya penyempurnaan dari kurikulum sebelumnya. Untuk mencapai tujuan pendidikan yang diharapkan seorang guru memerlukan konsep pengelolaan kelas yang efektif. Dalam suatu kegiatan belajar mengajar guru harus mampu menarik perhatian siswa yang dilakukan secara efektif dan efisien, oleh sebab itu pembelajaran harus dibuat semenarik mungkin dan mudah dipahami oleh siswa (Slameto, 2015 dalam Weranti 2017:34). Salah satu untuk menunjang pelaksanaan pembelajaran ialah dengan menggunakan media pembelajaran sebagai wahana penyampai pesan kepada siswa. Dimana siswa memperoleh pesan dengan kongkrit, dalam proses belajar siswa dapat sambil bermain dan mengenali lingkungan sesungguhnya. Hal tersebut sesuai dengan pernyataan Dwi Sunar, 2008 (Darajati, 2016:298) salah satu hal yang dapat dilakukan agar siswa dapat belajar sambil bermain yaitu dengan memodifikasi media permainan menjadi media pembelajaran.

Sukmadinata 2004 (Sugiaryo, dkk. 2015:617) lebih memandang pembelajaran tematik sebagai suatu model pembelajaran dengan fokus pada bahan ajaran. Bahan ajaran disusun secara terpadu dan dirumuskan dalam bentuk tema pembelajaran. Tema yang dimaksud adalah pokok pikiran atau gagasan pokok yang menjadi inti pembicaraan. kehadiran media pembelajaran sangatlah penting dan mengoptimalkan pelaksanaan pembelajaran. Oleh sebab itu media dan pembelajaran kini menjadi satu kesatuan yang saling mendukung. Untuk mendapatkan kualitas media pembelajaran yang baik agar dapat memberikan pengaruh yang signifikan dalam proses belajar mengajar, maka diperlukan pemilihan dan perencanaan penggunaan media pembelajaran yang baik dan tepat. Media adalah sebuah alat yang mempunyai fungsi menyampaikan pesan (Bovee, 1997 dalam Setiawan 2006:4). Arsyad 2013( Mustaqim 2016: 177) "menjelaskan bahwa agar proses belajar mengajar dapat berhasil dengan baik, siswa sebaiknya diajak untuk memanfaatkan semua alat inderanya."

Menurut Nana Sudjana, 2011 (Krisnawati 2013: 2) media tiga dimensi merupakan alat peraga yang memiliki panjang, lebar dan tinggi. apabila dijelaskan maka pengertian media pembelajaran tiga dimensi, yaitu media yang tampilannya dapat diamatidari arah pandang mana saja dan mempunyai dimensi panjang, lebar,dan 
tinggi/tebal. Kebanyakan media tiga dimensi merupakan obyek sesungguhnya atau miniatur obyek. Media tiga dimensi juga dapat diartikan sekelompok media tanpa proyeksi yang penyajiannya secara visual tiga dimensi. Tujuan penggunaan media tiga dimensi (benda tiuran) menurut Daryanto (2010:30-31) antara lain:

1. Mengatasi kesulitan yang muncul ketika mempelajari obyek yang terlalu besar.

2. Untuk mempelajari obyek yang telah menjadi sejarah di masa lampau.

3. Untuk mempelajari obyek yang tak terjangkau secara fisik.

4. Untuk mempelajari obyek yang mudah dijangkau tetapi tidak memberikan keterangan yang memadai.

5. Untuk mempelajari konstruksi-konstruksi yang abstrak.

6. Untuk memperlihatkan proses dari obyek yang luas.

Kelompok media ini dapat berwujud sebagai benda asli baik hidup maupun mati, dan dapat berwujud sebagai tiruan yang mewakili aslinya. Media tiga dimensi yang digunakan adalah jenis Diorama, yaitu sebuah pemandangan 3 dimensi mini bertujuan menggambarkan pemandangan sebenarnya. Diorama sebagai media pembelajaran dijelaskan oleh Sanaky 2013 (Anggraeni 2017:3) terutama berfungsi untuk mata pelajaran ilmu bumi (IPA), ilmu hayat, sejarah, bahkan diusahakan untuk berbagai mata pelajaran lainnya. Sehingga dapat disimpulkan bahwa media diorama dapat digunakan untuk hampir semua mata pelajaran. Media diorama ini dapat berwujud sebagai benda asli baik hidup maupun mati, dan dapat berwujud sebagai tiruan yang mewakili aslinya. Benda asli ketika akan difungsikan sebagai media pembelajaran dapat dibawa langsung ke kelas, atau siswa sekelas. Berdasarkan hasil penelitian oleh Anggraeni (2017:6) bahwa penggunaan media diorama dapat meningkatkan hasil belajar IPA tentang daur air siswa kelas V SDN Gempolsari Tanggulangin dan penelitian telah mencapai keberhasilan.

$$
\text { Ismilasari dan Hendratno }
$$
mengemukakan bahwa bentuk diorama terdiri dari bagian depan yang berisikan pemandangan dengan realita dan model, dan latar belakang yang dibuat agar memberikan efek seperti nyata. Apabila benda aslinya sulit untuk dibawa ke kelas atau kelas tidak mungkin dihadapkan langsung ke tempat dimana benda itu berada, maka benda tiruannya dapat pula berfungsi sebagai media pembelajaran yang efektif. Pembuatan media tiga dimensi jenis diorama dibuat tidak hanya mengacu atau terfokus pada satu mata pelajaran saja namun media tersebut mencakup beberapa mata pelajaran yang disatukan dalam satu tema. Sehingga perlu adanya pendampingan atau pelatihan dalam pembuatan media tiga dimensi jenis diorama yang berbasis tematik integratif agar guru dapat mengasah kreatifitasnya dan dapat memberikan pengalaman belajar yang bermakna.

Langkah-langkah pembuatan media diorama diantaranya: 1) menentukan tema yang akan dibuat sesuai dengan materi pelajaran; 2) membuat sketsa cakupan materi; 3) membuat rancangan diorama; 4) menyiapkan peralatan dan bahan; 5) membuat bingkai yang alas media yang akan digunakan; 5) membuat latar media; 6)membuat dataran; 7)menambahkan hal-hal detail; 8) melengkapi figure tambahan dalam media misalnya rumput, 
bebatuan, sungai, jembatan, hewan miniature atau tokoh lainnya; 9)tahap finishing.

Pelatihan yang ditargetkan dalam kegiatan ini sebagai bahan evaluasi kedepan agar menjadi perhatian bagi pemangku pendidikan terutama kepala sekolah dan guru di sekolah dasar dalam menghadirkan pembelajaran yang berkualitas bagi siswa melalui media pembelajaran tiga dimensi jenis diorama dalam pelaksanaan pembelajaran tamatik terintegrasi, guru diharapkan memiliki kecakapan dalam mengaitkan pembelajaran dengan kehidupan sehari-hari atau pengalaman siswa berbantuan media yang digunakan. Melalui media diorama dapat berwujud sebagai tiruan yang mewakili aslinya sehingga siswa dapat memperdalam pemahamannya tentang materi yang dipelajarinya.

Setelah kegiatan pengabdian kepada masyarakat ini, maka hasil yang ditargetkan adalah kemampuan guru dalam memdesain media pembelajaran tiga dimensi jenis diorama berbasis tematik integratif di sekolah dasar. Berbicara tentang media pembelajaran tentu memiliki beragam jenis, dan banyak lagi media pembelajaran yang mengacu pada perkembangan teknologi dengan melibatkan programer menarik sesuai dengan perkembangan teknologi, namun pada program ini lebih fokus pada pembuatan media jenis diorama karena media ini mampu memancarkan keterampilan seni dan menggambarkan obyek nyata dalam bentuk tiruan.

Sehingga secara tidak langsung, media ini telah merangsang nilai karakter siswa dalam mencintai keindahan, seni kreatifitas dan memberikan pengalaman belajar yang lebih bermakna karena diperlihatkan langsung dengan obyek sasaran yang tidak bisa dihadirkan wujud aslinya didalam kelas.

\section{METODE}

Khalayak sasarannya ialah guru SD Negeri I Topa, dimana sekolah ini secara geografis terletak di pesisir pantai dan letaknya bukan dititik pusat kota. Dari peninjauan secara keseluruhan lingkungan fisik sekolah belum termasuk sekolah unggulan dengan dukungan sarana dan prasarana yang masih kurang memadai, begitupun ketika memasuki kelas-kelas yang ada disana, masih terpantau sunyi atau sepi penggunaan media, baik media pajangan dalam kelas maupun yang digunakan dalam proses belajar mengajar. Sehingga perlu adanya kami berkunjung untuk saling berbagi tentang perlunya menghadirkan media ditengah-tengah proses pembelajaran begitupun media pajangan untuk memperindah desain lingkungan fisik kelasnya, dengan harapan siswa lebih termotivasi dan senang dengan ruang belajarnya. Karena bukan lagi hal lazim dari beberapa alasan guru tidak menghadirkan media, yaitu karena keterbatasan biaya, waktu dan juga pengalaman dalam mendesain media, maka juga dihadirkan tahap-tahap pembuatan media diorama dengan penggunaan bahan-bahan bekas yang minim biaya.

Metode kegiatan yang digunakan adalah dengan mengadakan kunjungan awal dalam rangka sosialisasi pentingnya pelibatan media pembelajaran dalam proses belajar mengajar dan selanjutnya akan memberikan pelatihan desain media tiga dimensi jenis diorama berbasis tematik integratif agar guru tidak hanya membuat media dengan titik fokus satu mata pelajaran saja, dan 
mendemonstrasikan tahapan-tahapan mendesain media diorama yang menarik dan sesuai dengan sub temanya. Kegiatan ini dilaksanakan ketika jam istrahat sehingga tidak menganggu jalannya proses belajar mengajar di sekolah.

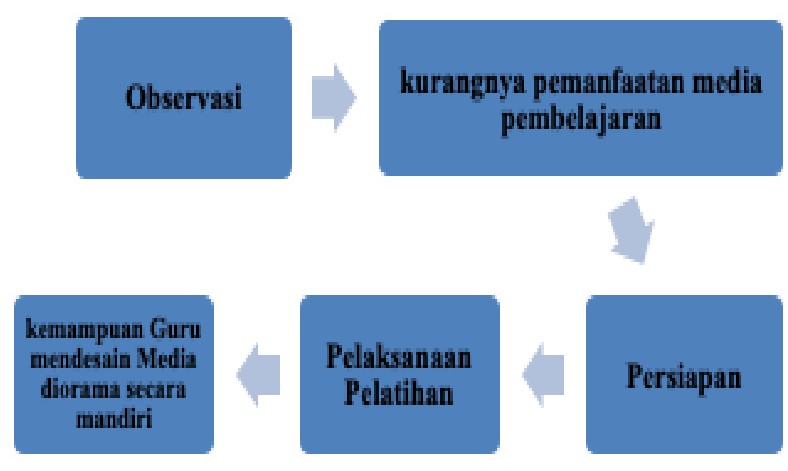

Gambar 1: Kerangka pemecahan masala

\section{HASIL DAN PEMBAHASAN}

Pelatihan ini diharapkan dapat memberikan jasa pelatihan pembuatan media pembelajaran interaktif. sehingga dapat meningkatkan kemampuan guru-guru dalam mempersiapkan penunjang pelaksanaan proses belajar mengajar di SDN 1 Topa. Dapat menyajikan pembelajaran kongkrit kepada siswa, dimana media diorama ini bertujuan untuk menggambarkan suasana sesungguhnya yang ada dilingkungan sekitar yang susah dihadirkan objeknya didalam kelas, sehingga dibuatlah media diorama yang menggambarkan objek yang sama dalam bentuk atau ukuran yang lebih kecil.

\section{Tahap persiapan}

Pada tahap persiapan, tim merancang desain awal media yang akan menjadi bahan praktik, dengan mengusung konsep alam dengan menetukan bentuk, ukuran, warna, dan bahan yang akan digunakan, melengkapi kelengkapan bahan-bahan dan alat pembuatan media. Alat dan bahan disediakan oleh pemateri, diantaranya koran, styrofoam, lem, gunting, manila karton, cat, benang, nilon, stick, kapas, dan miniatur hewan.

2. Tahap pelaksanaan

Tahap pelaksanaan kegiatan dilaksanakan di SD Negeri 1 Topa yang diikuti oleh Guru. Pelaksanaan kegiatan berlangsung sekitar 180 menit diwaktu jam pulang sekolah, sehingga tidak mengganggu berjalannya proses belajar mengajar di sekolah.

a. Pendahuluan

Tahap pendahuluan diawali dengan pengenalan konsep seputar media tiga dimensi dan peran media terhadap pembelajaran. Pemaparan materi sekitar 60 menit untuk memberikan pemahaman awal kepada peserta agar menumbuhkan motivasi diri dalam memenuhi kebutuhan siswa di sekolah dasar yang secara psikologis anak di usia tersebut merupakan fase kongkrit dalam artian, memandang sesuatu hal berdasarkan sesuatu yang dapat dilihatnya dan disentuhnya. Sehingga siswa dihadapkan dengan proses belajar mengajar yang nyata dan dapat melihat obyek yang sesungguhnya dalam bentuk ukuran yang berbeda. Media ini merupakan diorama yang menghadirkan karya tiga dimensi yang menyerupai obyek sasaran namun dalam bentuk yang mudah dibawa kedalam kelas atau ruangan. Media diorama yang dibuat mencakup materi pelajaran tematik sehingga media tidak hanya menampilkan satu mata pelajaran saja, melainkan dalam bentuk tematik. Setelah pemaparan materi seputar konsep 
media pembelajaran dan peran media diorama terhadap proses pembelajaran, selanjutnya penyampaian materi tentang Langkah-langkah pembuatan media diorama dan menampilakan video pembuatan media diorama yang telah dirancang oleh pemateri sebagai pengenalan awal kepada peserta bentuk dan cara pembuatan media. Kegiatan ini berlangsung sekita 30 menit.

b. Praktik

Tahap kegiatan praktik, pemateri menampilkan bahan-bahan dan alat pembuatan media diorama yang akan digunakan. Selanjutnya peserta dibagi kedalam dua kelompok. Jumlah peserta yang hadir sebanyak 10 guru sehingga pembagian kelompok dibagi menjadi dua, dengan jumlah anggota kelompok masingmasing terdiri dari 5 orang. Tujuan dibentuknya kelompok praktik agar menjadi motivasi tersendiri dan membangun semangat Kerjasama antar tim dalam menyelesaikan target kemampuan dari perolehan materi sebelumnya. Masingmasing kelompok disediakan bahan yang akan digunakan. Sebelum masuk pada tahap uji coba oleh kelompok peserta, terlebih dahulu pemateri mempraktikkan tahapan pembuatan media media diorama yang sudah dirancang sebelumnya.

c. Uji coba peserta

Tahapan terakhir adalah uji coba peserta yang dilakukan selama 90 menit. Masingmasing kelompok memulai mendesain medianya dengan mengingat acuan dari materi, video dan praktik langsung oleh pemateri pada sesi sebelumnya. Selama proses pembuatan media terpantau guru sangat antusias dan bekerjasama antar satu sama lain. Selama proses uji coba pembuatan media oleh peserta, ada beberapa keterampilan yang dinilai diantaranya kekompakan, kesesuaian urutan pembentukan media diorama, kreatifitas, kerapihan, kesesuaian dengan pembelajaran tematik, dan ketepatan waktu dalam menyelesaikan.

Dari keenam komponen penilaian, 98\% berjalan dengan baik dan menghasilkan karya sesuai dengan harapan meskipun media yang dibuat hanya mencakup dua mata pelajaran saja didalamnya yaitu tema Lingkungan kelas 2 SD. Mencakup mata pelajaran IPA tentang mengenal bagianbagian hewan dan tumbuhan. Dan untuk mata pelajaran Bahasa Indonesia yaitu membuat puisi dengan tema lingkungan. Kegiatan terakhir adalah mempersentasekan hasil karya dari masing-masing kelompok dengan menyampaikan manfaat dan fungsi dari medianya dan tujuan pembelajaran yang ingin dicapai dengan bantuan media diorama.

d. Penutup

Kegiatan penutup, seluruh peserta diberikan apresiasi atas keterlaksanaan kegiatan dan feedback atas pelaksanaan pelatihan pembuatan media diorama, sebagai bahan refleksi bagi tim pelaksana untuk perbaikan apabila ada kekurangan dalam pelaksanaan kegiatan dan tentunya menjadi perbaikan pada kegiatan selanjutnya. Melalui kegiatan 
pelatihan pembuatan media, diharapkan guru dapat menambah wawasan dan referensi dalam membuat media di kelas dan memudahkan guru dalam merancang media yang sesuai dengan kebutuhan siswanya dan tentunya sesuai dengan kurikulum 2013 yang mengacu pada pembelajaran tematik integratif.

Tabel 1 mengaskan bahwa pelaksanakan kegiatan pelatihan media diorama sangatlah bermanfaat dan memiliki pengalaman tersendiri oleh peserta dan lebih menambah khisana pengetahuan seputar media pembelajaran tiga dimensi serta pemanfaatannya.

\section{SIMPULAN}

Program

pendampingan

dapat

diselenggarakan dengan baik dan berjalan dengan lancar sesuai dengan rencana kegiatan yang telah disusun mulai dari kegiatan pendahuluan, pelaksanaan, hingga kegiatan penutup. Semua peserta ikut terlibat aktif dalam kegiatan dan saling bertukar pendapat dalam mendesain medianya, sehingga terjalin Kerjasama yang baik dan sharing kreatifitas. Sehingga menjadi semangat tersendiri bagi pemateri untuk melakukan kegiatan pelatihan-pelatihan lainnya.

Tabel 1 Perbandingan Sebelum dan Setelah Pelaksanaan Pelatihan

\begin{tabular}{|c|l|l|l|}
\hline No & \multicolumn{1}{|c|}{ Kondisi awal } & \multicolumn{1}{|c|}{ pelaksanaan } & \multicolumn{1}{c|}{ Uji coba } \\
\hline 1. & Minimnya penggunaan media & $\begin{array}{l}\text { Diberi wawasan tentang konsep media, } \\
\text { pentingnya pemanfatan media, dan analisis } \\
\text { kebutuhan siswa secara kongkrit }\end{array}$ & $\begin{array}{l}\text { Memahami konsep media, dan } \\
\text { keberfungsian suatu media, serta } \\
\text { memberikan kemudahan kepada guru } \\
\text { dalam menyampaikan pesan. }\end{array}$ \\
\hline 2. & $\begin{array}{l}\text { Belum memiliki keterampilan } \\
\text { mengembangkan media diorama }\end{array}$ & $\begin{array}{l}\text { Dilatih keterampilan mendesain media } \\
\text { diorama melalui pemutaran video dan } \\
\text { praktik langsung oleh pemateri }\end{array}$ & $\begin{array}{l}\text { Memiliki keterampilan dalam } \\
\text { mendesain media diorama dengan } \\
\text { kreativitas oleh peserta }\end{array}$ \\
\hline 3. & $\begin{array}{l}\text { Belum memiliki pengalaman dalam } \\
\text { membuat media secara gotong } \\
\text { royong }\end{array}$ & $\begin{array}{l}\text { Dilatih melalui Kerjasama kelompok dan } \\
\text { menyatukan ide-ide kreatif dalam satu karya }\end{array}$ & $\begin{array}{l}\text { Memiliki pemahaman dan menambah } \\
\text { pengetahuan serta pengalaman dalam } \\
\text { membuat media dan berkreasi melalui } \\
\text { ide-ide teman kelompok dan dari } \\
\text { kelompok lain. }\end{array}$ \\
\hline
\end{tabular}

Berdasarkan evaluasi yang telah dilakukan dapat diajukan beberapa saran sebagai berikut: 1) Bagi sekolah baiknya mengkomunikasikan kebutuhan-kebutuhan bapak/ibu guru di sekolah dalam artian yang menunjang kompetensi guru dan menjalin Kerjasama dengan pihak Universitas terkait dengan pengembangan kualitas pendidikan.; 2) Bagi guru, Ketika ada pelatihan dalam meningkatkan kinerja profesi kita sebaiknya selalu ikut serta dalam kegiatan karena hal ini merupakan kebutuhan pokok bagi guru sebagai profesi yang professional yang terus mengembangkan dan memperbaharui kelimuannya.

\section{UCAPAN TERIMA KASIH}

Ucapan terimakasih atas dukungan dari tim pelaksana atas berjalannya Kegiatan ini dengan lancar dan penuh kekompakan. Tak luput pula Ucapan terimakasih atas support secara materil dan non materil kepada jajarán pimpinan universitas Muhammadiyah Buton. Seluruh stakeholder SD 
Negeri 1 Topa yang telah memberikan kesempatan untuk sharing pengalaman dan bekerjasama dalam memajukan kualitas pembelajaran. Ucapan terimakasih kapada tim mahasiswa yang telah ikut serta berpartisipasi dalam kelancaran pelaksanaan kegiatan sekaligus menambah wawasan dan pengalaman di lapangan.

\section{DAFTAR PUSTAKA}

Information J and Education C T $2017 \mathrm{E}$. ISSN . $2541 \quad-5107$ DOI Link : https://doi.org/10.21070/jicte.v1i1.1127 Journal Homepage : http // ojs . umsida . ac . id / index . php / jicte Original Research Articles Pengaruh Media Diorama Tiga Dimensi Terhadap Hasil Belajar Kognitif Materi Mengenal Penggunaan Uang Pada Mapel IPS Kelas III SDN Balong Bowo . Fakultas Keguruan dan Ilmu Pendidikan, Universitas Muhammadiyah Sidoarjo, Jl .

Yogyakarta U N 2016 PENGEMBANGAN MEDIA DIORAMA LINGKUNGAN ( DOLAN ) SEBAGAI MEDIA PEMBELAJARAN IPS KELAS III SDN TAHUNAN THE DEVELOPMENT OF ENVIRONMENT DIORAMA AS A SOCIAL LEARNING MEDIA IN 3 th

Anon 2015 No Title XXVII 615-24

Setiawan I, Pendidikan J and Fpips G Peningkatan Kualitas Pembelajaran Geografi Melalui Pengembangan Media Pendidikan Oleh: Iwan Setiawan*)

\section{Mustaqim I 2016 PEMANFAATAN AUGMENTED REALITY SEBAGAI MEDIA PEMBELAJARAN 13 174-83}

Media P, Untuk D, Keterampilan P and Karangan M PENGGUNAAN MEDIA DIORAMA UNTUK PENINGKATAN KETERAMPILAN MENULIS KARANGAN NARASI PADA SISWA SEKOLAH DASAR Yaashinta Ismilasari
Media P, Dimensi T, Media P, Dimensi $\mathrm{T}$ and Tematik P PENGGUNAAN MEDIA TIGA DIMENSI UNTUK MENINGKATKAN HASIL BELAJAR DI SEKOLAH DASAR Ari Krisnawati 1-7

Daryanto (2010). Media Pembelajaran. Yogyakarta: Gava Media. 